\title{
Correction to: Delayed appearance of mature ganglia in an infant with an atypical presentation of total colonic and small bowel aganglionosis: a case report
}

Fereshteh Salimi Jazi ${ }^{1 \dagger}$, Julia M. Chandler ${ }^{2 \dagger}$, Chad M. Thorson ${ }^{3}$, Tiffany J. Sinclair ${ }^{2}$, Florette K. Hazard ${ }^{4}$, John A. Kerner ${ }^{5}$, Sanjeev Dutta, James C. Y. Dunn ${ }^{2}$ and Stephanie D. Chao ${ }^{2^{*}}$

\section{Correction to: BMC Pediatrics}

https://doi.org/10.1186/s12887-019-1456-0

Following publication of the original article [1], the authors reported error on the images/figures used which also resulted in un-sequential order. The updated figures and captions are provided below.

* Correspondence: sdchao@stanford.edu

${ }^{\dagger}$ Fereshteh Salimi Jazi and Julia M. Chandler contributed equally to this work.

${ }^{2}$ Division of Pediatric Surgery, Department of Surgery, Stanford University

School of Medicine, 300 Pasteur Drive, Always Building M116, MC: 5733,

Stanford, CA 94305, USA

Full list of author information is available at the end of the article 


\begin{tabular}{|c|c|c|c|c|c|c|c|}
\hline $\begin{array}{r}\text { Procedures \& } \\
\text { Diagnostic Studies }\end{array}$ & $\begin{array}{c}\text { Presents with } \\
\text { bilious emesis; } \\
\text { KUB - no air } \\
\text { past jejunum; } \\
\text { gastrografin } \\
\text { enema - } \\
\text { microcolon, } \\
\text { unused distal } \\
\text { ileum }\end{array}$ & 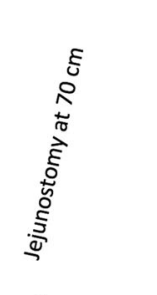 & $\begin{array}{l}\text { Transferred to } \\
\text { our hospital }\end{array}$ & 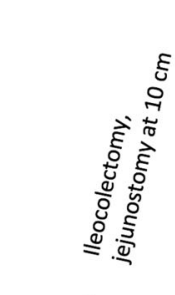 & 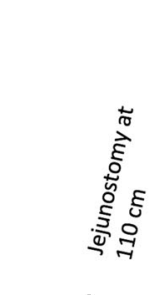 & $\begin{array}{l}\text { Serial small bowel } \\
\text { follow throughs with } \\
\text { progressive intestinal } \\
\text { dilation }\end{array}$ & 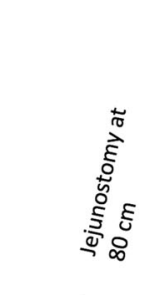 \\
\hline Age & Od & $1 d$ & $17 \mathrm{~d}$ & $30 d$ & $7 \mathrm{mo}$ & & $34 \mathrm{mo}$ \\
\hline $\begin{array}{r}\text { Jejunal } \\
\text { Pathology }\end{array}$ & $\begin{array}{r}\text { Aga } \\
\text { jejuny }\end{array}$ & $\begin{array}{l}\text { glionic distal } \\
\text { n, ileum, colon, } \\
\text { dd rectum }\end{array}$ & $\begin{array}{c}\text { Permanent: } \\
\text { Hypoganglionated } \\
\text { at } 70 \mathrm{~cm}\end{array}$ & $\begin{array}{c}\text { Frozen: } \\
\text { Aganglionic } \\
\text { distal to } 10 \mathrm{~cm} \\
\text { Permanent: } \\
\text { Aganglionic } \\
\text { distal to } 16 \mathrm{~cm}\end{array}$ & $\begin{array}{c}\text { Frozen: } \\
\text { Aganglionic } \\
\text { distal to } 35 \mathrm{~cm} \\
\text { Permanent: } \\
\text { Aganglionic } \\
\text { distal to } 45 \mathrm{~cm}\end{array}$ & & $\begin{array}{l}\text { Frozen: Not } \\
\text { performed } \\
\text { Permanent: } \\
\text { Aganglionic } \\
\text { distal to } 43 \mathrm{~cm}\end{array}$ \\
\hline
\end{tabular}
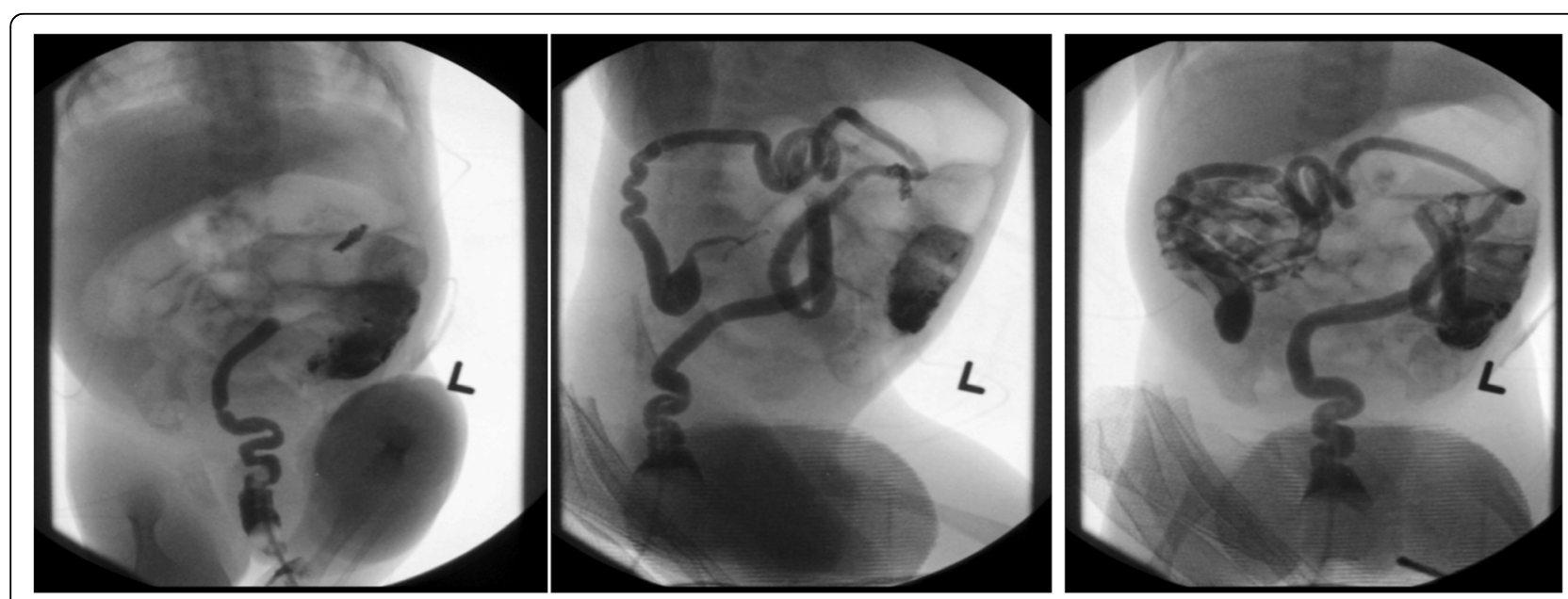

Fig. 2 Gastrografin enema obtained at birth demonstrating a microcolon and narrow caliber distal ileum with absence of filling of the ileum 
A. DOL 1 surgery (performed at referring facility)

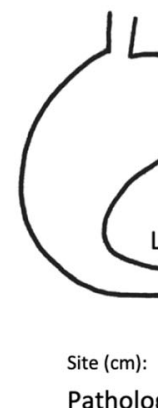

Key

$+=$ ganglion cells

= no ganglion cells

B. DOL 30 surgery
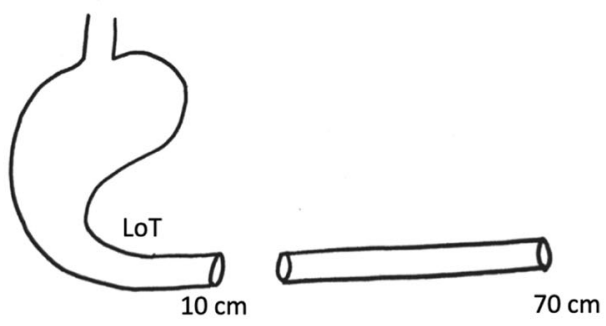

Site $(\mathrm{cm}): 10 \quad 13 \quad 16 \quad 2030 \quad 354047525765 \quad 67 \quad 72$

Frozen: +

Final: $+++\ldots \ldots$

C. 7 mos surgery

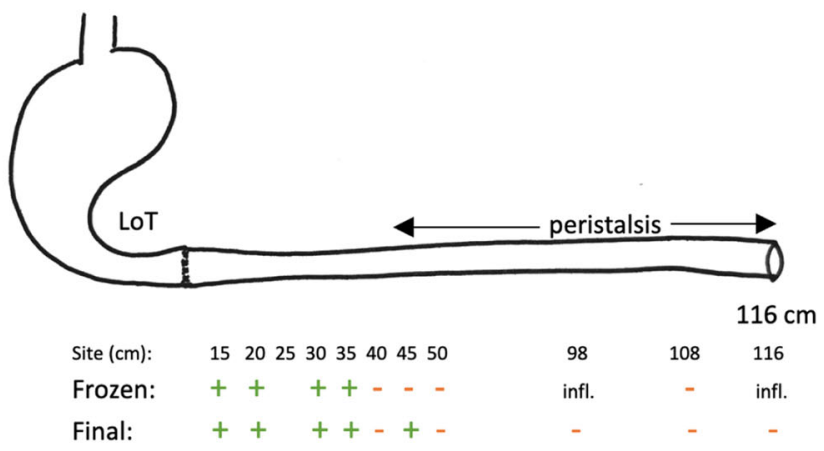

D. 34 mos surgery

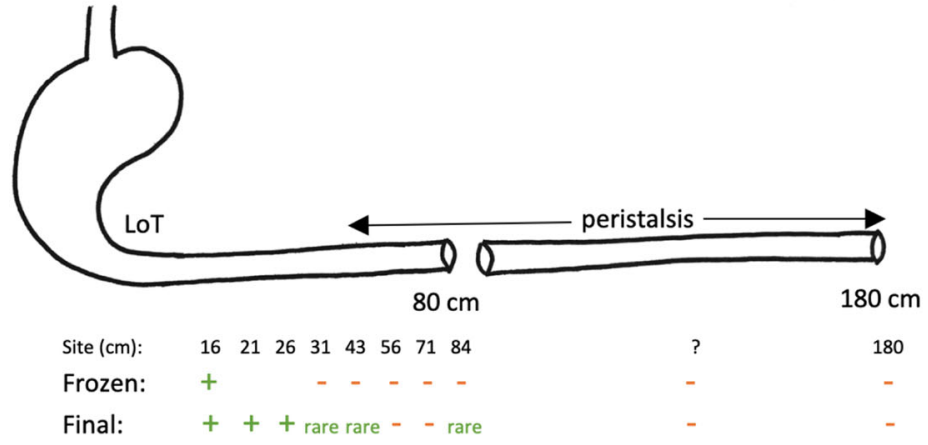

Fig. 3 Illustration of surgeries and biopsy results. a DOL1 surgery (at referring institution). b DOL 30 surgery. c 7 month surgery. d 34 month surgery 

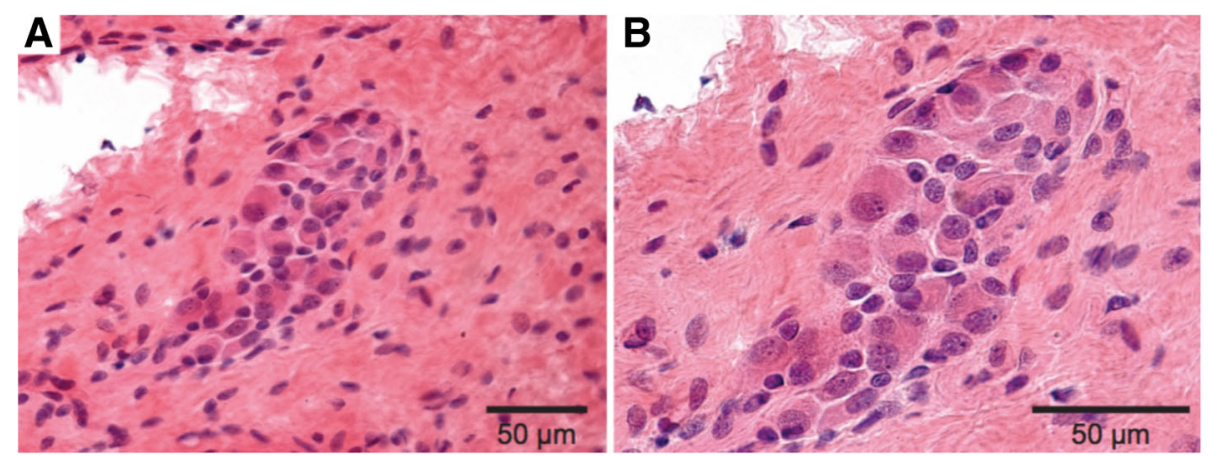

Fig. 4 Submucosal ganglion cells in previously aganglionic bowel. a Cluster of submucosal ganglion cells (H\&E, 400X). b Higher power magnification of submucosal ganglion cells (H\&E, 600X)

The original article has been corrected.

\section{Author details}

'Department of Surgery, University of Texas at Galveston, 301 University Blvd, Galveston, TX 77555, USA. ${ }^{2}$ Division of Pediatric Surgery, Department of Surgery, Stanford University School of Medicine, 300 Pasteur Drive, Always Building M116, MC: 5733, Stanford, CA 94305, USA. ${ }^{3}$ Division of Pediatric Surgery, Department of Surgery, University of Miami Health System, 1120 NW 14th Street, Suite 450, Miami, FL 33136, USA. ${ }^{4}$ Department of Pathology, Stanford University School of Medicine, 300 Pasteur Drive Rm H2110,

Stanford, CA 94305, USA. ${ }^{5}$ Department of Pediatrics - Gastroenterology, Stanford University School of Medicine, 730 Welch Rd 2nd Fl, Palo Alto, CA 94304, USA.

Published online: 28 May 2019

\section{Reference}

1. Salimi Jazi F, Chandler JM, Thorson CM, Sinclair TJ, Hazard FK, Kerner JA, Dutta S, Dunn JCY, Chao SD. Delayed appearance of mature ganglia in an infant with an atypical resentation of total colonic and small bowel aganglionosis: a case report. BMC Pediatrics. https://doi.org/10.1186/s12887019-1456-0 